Foro Interno. Anuario de Teoría Política

ISSN: $1578-4576$

http://dx.doi.org/10.5209/FOIN.61512

\title{
Problemática y perspectivas sobre la temporalidad histórica: algunas consideraciones para una historia de la teoría política ${ }^{1}$
}

\author{
Sergio Javier Barrionuevo ${ }^{2}$
}

Recibido: 9 de octubre de 2017/ Aceptado: 2 de abril de 2018

Resumen. El renovado interés que ha adquirido el pensamiento político desde la segunda mitad del siglo veinte ha dado lugar a nuevas perspectivas para su estudio. Sin embargo, el desarrollo teórico de las ciencias sociales no ha tenido una interacción fluida entre las disciplinas que la componen. En este trabajo argumentaré que los desarrollos metodológicos sobre la posibilidad histórica de la teoría política deberían estar interconectados con los desarrollos en el campo de la historiografía. Para sostener mi posición me propongo realizar una aproximación problemática en torno a la posibilidad de construir un conocimiento histórico-científico de la teoría política, a partir de los siguientes tópicos: (1) la temporalidad histórica; (2) el vínculo entre temporalidad y pensamiento, y (3) la politización del pensamiento. Palabras clave: pensamiento político; teoría política; "lo político"; temporalidad histórica.

\section{[en] Problems and Perspectives of Historical Temporality: Some Remarks for a History of Political Theory}

\begin{abstract}
Renewed interest in political thought since the second half of the twentieth century has favoured the development of new perspectives. However, theoretical developments in the social sciences have not been carried out through fluid interaction among the disciplines that compose this field of study. In this article I argue that methodological developments regarding the historical possibility of constructing any broad political theory should be interconnected with developments in the field of historiography. To validate this perspective, I propose an approach that addresses the problems arising from the challenge of building a historical-scientific knowledge of political theory, focusing on the following topics: (1) historical temporality; (2) the link between temporality and thought; and (3) the politicisation of thought.
\end{abstract}

Keywords: political thought; political theory; "the political"; historical temporality.

Cómo citar: Sergio Javier Barrionuevo, "Problemática y perspectivas sobre la temporalidad histórica: algunas consideraciones para una historia de la teoría política": Foro Interno. Anuario de Teoría Política, vol. 18 (2018), pp. 99-123.

1 Este artículo fue realizado con el apoyo de una beca doctoral de CONICET y fue elaborado en el marco del Proyecto UBACyT 2013-2016 (Código: 20020120100073), dirigido por Julián Gallego y Carlos García Mac Gaw en la Universidad de Buenos Aires (Argentina). También está vinculado a las actividades desarrolladas en los Proyectos ICI-UNGS 2015-2016 (Código: 30/1109), dirigido por Marta Madero y Eleonora Dell'Elicine en la Universidad Nacional de General Sarmiento (Argentina) y PICT-2015-2064 (Res. 240/16), dirigido por Diego Paiaro en la Agencia Nacional de Promoción Científica y Técnica (Argentina).

2 Universidad Nacional de General Sarmiento / Universidad de Buenos Aires / CONICET (Argentina) E-mail: sjbarrionuevo@gmail.com 


\section{Presentación}

El renovado interés que ha adquirido el pensamiento político desde la segunda mitad del siglo veinte ha dado lugar a nuevas perspectivas para su estudio. Sin embargo, debido a motivos externos al propio desarrollo teórico de las ciencias sociales, la interacción entre las disciplinas que las componen no ha sido tan fluida como se esperaría.

En este trabajo argumentaré que los desarrollos metodológicos sobre la posibilidad histórica de la teoría política deberían estar interconectados con los desarrollos en el campo de la historiografía. Sin embargo, realizar una historia de la teoría política implica una serie de problemas de diverso orden, entre los que me interesa destacar los siguientes: epistemológicos, metodológicos e historiográficos. En primer lugar, podemos decir que arribamos a un problema epistemológico en tanto se propone realizar una "historia", esto es, construir un discurso capaz de dar cuenta científicamente del fenómeno estudiado en su dimensión histórica ${ }^{3}$. Ello lo vincula intrínsecamente, a su vez, con las otras dos dimensiones señaladas: por un lado, de qué modo se puede aprehender dicho fenómeno sobre el cual construimos nuestro discurso (dimensión metodológica del problema) y, por otra parte, en qué consiste la naturaleza "histórica" de dicho fenómeno (dimensión historiográfica del problema). Para ello en este trabajo abordaré tres cuestiones: el problema de la temporalidad histórica $(\S 1)$, la discusión acerca del vínculo entre temporalidad y pensamiento $(\S 2)$ y la politización del pensamiento $(\S 3)$.

\section{La temporalidad histórica}

\subsection{El tiempo de la ciencia histórica: la dialéctica sujeto-objeto}

Javier Fernández Sebastián, siguiendo en cierta medida los lineamientos de Reinhart Kosselleck (1923-2006) aunque tratando de trazar las bases para una "historia de la conciencia histórica", sostenía que:

A finales del siglo XVIII y principios del XIX, coincidiendo con la Ilustración tardía, las revoluciones atlánticas y el auge y caída del Imperio napoleónico, el mundo occidental entró en un período de cambios incesantes y acelerados. Se produjo entonces una transformación decisiva que afectó a la mayoría de los conceptos socio-políticos fundamentales, e indirectamente también a las nacientes ciencias sociales. Al tiempo que se acuñaban términos nuevos referentes a movimientos políticos como liberalismo, conservadurismo, progresismo, republicanismo o socialismo, conceptos tan básicos como historia, sociedad y Estado iniciaron

\footnotetext{
En este trabajo nos referimos a la ciencia como "discurso" en sentido foucaulteano, ya sea tomado tanto como episteme en cuanto "lo que define las condiciones de posibilidad de todo saber" (Michel Foucault, Las palabras y las cosas, Siglo XXI, Buenos Aires, 2002, p. 183); como formation discursive en tanto "un conjunto de reglas anónimas, históricas, ... que han definido en una época dada,... las condiciones de ejercicio de la función enunciativa" (Michel Foucault, La arqueología del saber, Siglo XXI, Buenos Aires, 2004, p. 198); o como "los elementos del dispositivo pertenecen tanto a lo dicho como a lo no dicho. El dispositivo es la red que puede establecerse entre estos elementos" (Michel Foucault, "El juego de Michel Foucault" [1977]: Diwan, n. ${ }^{\circ} 2$ y 3 (1978), p. 172).
} 
una nueva vida. Dicha transformación semántica vino acompañada de una nueva temporalidad, esto es, de una concepción del tiempo histórico alternativa a la anteriormente vigente, así como de la consolidación e institucionalización progresiva de las ciencias históricas, sociales y políticas ${ }^{4}$.

Encuadrar la experiencia del tiempo histórico abierta por la Ilustración tardía en el plano del discurso científico implica una re-estructuración de la lógica en la cual se inscriben los enunciados. Ahora bien, tal como fue demarcado en el contexto de institucionalización de la ciencia histórica en el siglo diecinueve esa lógica se articula en torno a la dialéctica gnoseológica entre sujeto-objeto ${ }^{5}$. Esta dialéctica se presenta como el presupuesto (Voraussetzungen), ya presente en el pensamiento hegeliano pero epistemológico e historiográficamente reconfigurado en el siglo diecinueve. Según este presupuesto habría una relación constitutiva entre lo subjetivo y lo objetivo en tanto polos opuestos que se necesitan mutuamente. Martin Heidegger (1889-1976) considera que estos conceptos operan en G. W. F Hegel (1770-1831) como "presu-puestos (pensantes)" [Voraus-setzungen (denkerischen)] en tanto son "puestos" (gesetzt) con la esencia del pensar en su negatividad'. En este sentido, según Heidegger, para Hegel el pensar histórico se despliega como "contra-posición" (Auseinandersetzung, lit. "poner uno frente a otro"), de modo que no solo es un retroceso (Rückgang), sino también un traslado (Ver-setzung) hacia aquello que "todavía no" (noch nicht) era permitido pensar. Sin embargo, para Heidegger la relación sujeto-objeto (Subjekt-Objekt-Beziehung) no es un fenómeno propio del pensamiento moderno en tanto determinación de la era de la técnica, sino que este pertenece al inicio del pensamiento occidental. Los griegos, a quienes Heidegger les atribuye este inicio, al concebir al hombre como "animal racional" hacen surgir la relación sujeto-objeto de "la experiencia inicial del ente como tal" ". Ello se debería a que, para el filósofo de Messkirch, los griegos constituyen "el primer comienzo" (der erste Anfang) que determina la pérdida de extrañeza (Befremdlichkeit) del ente, en tanto lo hace ingresar en el ámbito del conocer (Bezirk des Sichauskennens) ${ }^{8}$. Asimismo, para Heidegger, Hegel quedaría ligado al "primer comienzo" (der erste Anfang) en tanto la Wirklichkeit es conceptualizada: "Entidad como representatividad de la razón absoluta" (Seiendeheit als Vorgestelltheit der absoluten Vernunft).

De acuerdo con esta dialéctica, por tanto, el fundamento de "lo real" quedaría establecido o bien por una determinación objetiva donde la exterioridad de las condiciones materiales establece las formas internas de estructuración de la conciencia, o bien por una constitución subjetiva en la cual la interioridad construye a la exterioridad desde sí misma. En este marco de referencia la temporalidad histórica es

4 Javier Fernández Sebastián, "Historia, historiografía, historicidad. Conciencia histórica y cambio conceptual", en Manuel Suárez Cortina (ed.), Europa del sur y América latina. Perspectivas historiográficas, Biblioteca Nueva, Madrid, 2014, p. 36.

5 Cf. Michel de Certeau, La escritura de la historia [1975], Universidad Iberoamericana, México, 2006, pp. 71-75.

6 Cf. Martin Heidegger, Meditación, Biblos, Buenos Aires, 2005, p. 43.

7 Cf. ibid., p. 159.

8 Cf. Martin Heidegger, Aportes a la Filosofia: acerca del evento, Biblos, Buenos Aires, 2003, pp. 223-224, 68$69,167$.

9 Cf. Heidegger, Hegel, en Gesamtausgabe, Bd. 68,Vittorio Klosterman, Frankfurt am Main, 1993, p. 10. Sobre la concepción hegeliana de la historia y su vínculo con la práctica historiográfica, ver Hayden White, Metahistoria, Fondo de Cultura Económica, Buenos Aires, 2010, pp. 86-132. 
pensada o bien en el plano de la exterioridad objetiva (tiempo cósmico), o bien en el de la interioridad subjetiva (tiempo de la conciencia) ${ }^{10}$.

Esta oposición establece una tensión entre tiempo objetivo y subjetivo, la cual se vio renovada recientemente a partir de la emergencia de los estudios sobre la memoria social. Ello se debe a que se abre, nuevamente, el debate en torno a qué es hacer historia y, por lo tanto, cuáles son los mecanismos que permiten distinguir la dimensión histórica del objeto estudiado, lo cual llevado al plano epistemológico implicaría pensar cuál es el contenido científicamente tematizable como histórico. Sin embargo, los modos de aproximación al conocimiento, ya sean estos gnoseológicos o epistemológicos, implican, tal como sostiene Willard Van Orman Quine (19082000), la presuposición de ciertos compromisos ontológicos acerca de la constitución de lo cognoscible ${ }^{11}$. Maurice Halbwachs (1877-1945), en su trabajo sobre la mémoire collective, lo ponía en evidencia:

La historia no comienza sino en el punto en el que termina la tradición, momento en el que se apaga o se descompone la memoria social. Mientras un recuerdo subsiste, es inútil fijarlo por escrito ${ }^{12}$.

Mientras, por un lado, la tradición representa el ámbito de la memoria social — la cual es concebida como una entidad frágil, carente de materialidad y, por ende, sujeta a la contingencia de la dinámica misma de una temporalidad objetiva que la trasciende y la desgasta - ; la historia, por otra parte, se sostendría sobre la materialidad de la escritura - la cual es presupuesta como un elemento inmutable, cuyo fundamento es la exterioridad de "lo que pasó", es decir, lo que no se puede cambiar-. En este sentido, cuando Yosef Hayim Yerushalmi (1932-2009) atribuye a la "historia de los historiadores" la capacidad de restituir el pasado perdido está presuponiendo la objetividad de la experiencia que la historia representa ${ }^{13}$. Ahora bien, objetivar la temporalidad histórica implica que el "contenido" de la historia es pensado en relación al espacio, es decir, se piensa el pasado como algo que se ha dejado "atrás", pero que se puede volver y recuperarlo tal como ocurrió. Esta espacialización de la temporalidad del tiempo es lo que Heidegger había denominado "la experiencia vulgar del tiempo" (die vulgäre Zeiterfahrung). Según esta concepción el tiempo es aquello que contiene (umhalt) "lo que pasó", constituyéndose en el ámbito mismo de la objetividad de los objetos, y permite ordenar, por tanto, la experiencia histórica en función de los operadores "anterior" y "posterior" 14 .

10 Cf. Michael Scheperd, "Tiempo de lo real y tiempo del lógos": Diógenes, n. ${ }^{\circ} 74$ (1971), pp. 31-44. Palti, a partir del debate modernidad-postmodernidad, considera que hablar de un "tiempo de la modernidad" es reducir a un único modo de la "temporalidad histórica" las diferentes concepciones del tiempo que surgen durante los cuatro siglos considerados como "modernos", cf. Elías J. Palti, Aporías: Tiempo, Modernidad, Historia, Sujeto, Nación, Ley, Alianza, Buenos Aires, 2001, pp. 21-31.

11 Willard Quine, “On What There Is", en From a Logical Point of View, Harper \& Row, New York, 1961, pp. 12-13.

12 Maurice Halbwachs, La memoria colectiva, Miño \& Dávila, Buenos Aires, 2011, p. 128.

13 Yosef Hayim Yerushalmi, "Reflexiones sobre el olvido", en Usos del olvido. Comunicaciones al coloquio de Royaumont, Nueva Visión, Buenos Aires, 1989, p. 23.

14 Martin Heidegger, Sein und Zeit [1927], Max Niemeyer Verlag, Tübingen, 2006, pp. 378-382. Esta tradición de "experiencia vulgar del tiempo" es atribuida por Heidegger a la concepción aristotélica del tiempo. Para un análisis de la lectura heideggeriana del tiempo en Aristóteles, ver Sergio Barrionuevo, "Khrónos y psykhé. Sobre una lectura heideggeriana de Aristóteles”, en Sebastián Torres y Julia Smolá (comps.), Lecturas contemporáneas de la filosofía política clásica y moderna, Universidad Nacional de General Sarmiento, Los Polvorines, 
En este sentido, la materialidad de la "experiencia histórica" de los agentes sociales se habría sostenido en el "ahora" del tiempo pasado, entendido este como un elemento objetivo y que puede ser restituido de manera racional en el "ahora" del historiador. Por esta razón, cuando Yerushalmi sostiene que el historiador trasciende la memoria colectiva para proponer una anamnesis capaz de "restaurar el pasado total" 15 , él presupone que el "tiempo de la historia" se da objetivamente y se puede restaurar racionalmente con un discurso que dé cuenta de la totalidad de los "ahoras-pasados". De modo que "lo histórico", en este sentido, es considerado como aquel "ahora" que "ya no está ahi" y que, a pesar de ser restituido a la presencia por medio del discurso, no ejerce eficacia sobre el presente. De esta manera, se lo reduce a ser aquello que es "reconocido" por medio del conocimiento histórico ${ }^{16}$.

Este presupuesto implica pensar la "temporalidad histórica" como espacio donde toda objetividad es posible, entendida esta como exterioridad. Asimismo, considera la "experiencia histórica" como restitución de los "ahoras-pasados" en un "ahora-presente", lo cual establece una línea de continuidad objetiva que instaura una ruptura con la subjetividad del historiador. Por lo tanto, "lo histórico" contenido en el relato consistiría en una organización de la "experiencia" acorde con la estructura objetiva de la "temporalidad histórica". Ahora bien, el carácter exterior de esta temporalidad operaría como garantía de objetividad del discurso histórico, lo cual permitiría diferenciarla en cuanto discurso científico de la práctica literaria $^{17}$. Por lo que la exterioridad del tiempo, dentro de esta perspectiva, funciona como elemento que garantiza el acceso a los "ahoras-pasados", lo cual permite la superación de las consecuencias escépticas de un historicismo relativista - esto es, considerar que cada época forja sus propios conceptos y por tanto no podemos acceder a ellos-, pero subsume a la práctica historiográfica en el compromiso ontológico en torno a la existencia de un plano histórico homogéneo capaz de mediar entre pasado (lenguaje de la fuentes) y presente (lenguaje del historiador) ${ }^{18}$. Aquí

2012, pp. 134-138. Para una discusión teórico-historiográfica del vínculo entre espacio y temporalidad histórica, ver Reinhart Koselleck, Zeitschichten. Studien zur historik, Suhrkamp, Frankfurt am Main, 2000, pp. 79-89.

15 Yerushalmi, "Reflexiones sobre el olvido", p. 23.

16 Esta posición suele ser denominada como visión "realista" — llamada así por presuponer epistemológicamente el "realismo científico", no en referencia a la corriente historiográfica del "realismo francés" (Stendhal, Balzac y Tocqueville) - , en tanto concibe la historia como descripción verdadera y objetiva de los eventos pasados, lo cual implica objetividad en la explicación, confianza en las fuentes, suponer una teoría pictórica del lenguaje para analizar el texto de las fuentes. Leopold von Ranke fue uno de los historiadores más influyentes entre quienes proponían una visión sostenida en una cierta visión de la historia en el marco de "realismo científico". Cf. Leopold von Ranke, Pueblos y Estados en la historia moderna, Fondo de Cultura Económica, México, 1948, p. 13. Cf. Hayden White, "Romanticism, Historicism, and Realism: Toward a Period Concept for Early Nineteenth-Century Intellectual History" [1968] y "The Discourse of History" [1979], reimpresos en The Fiction of Narrative: Essays on History, Literature, and Theory (1957-2007), The Johns Hopkins University Press, Baltimore, 2010, pp. 68-79 y 187-202; Hayden White, “Against Historical Realism. A Reading of War and Peace": New Left Review, n. 46 (2007), pp. 89-110; Eugen Zeleňák, "Two Versions of a Constructivist View of Historical Work": History and Theory, vol. 54, n. ${ }^{\circ} 2$ (2015), p. 211.

17 Cf. Hayden White, "El valor de la narrativa en la representación de la realidad" [1980], en El contenido de la forma. Narrativa, discurso y representación histórica, Paidós, Buenos Aires, 1992, pp. 17-39; Ivan Jablonka, "Las operaciones de veridicción", en La historia es una literatura contemporánea. Manifiesto por las ciencias sociales, Fondo de Cultura Económica, Buenos Aires, 2016, p. 169-194.

18 En este sentido sostiene De Certeau, La escritura de la historia, p. 23, con tono crítico: “... el pasado nos resulta ficción del presente; lo mismo pasa en todo trabajo historiográfico verdadero. La explicación del pasado nunca deja de marcar la distinción entre el aparato explicativo, que es presente, y el material explicado: los documentos que se refieren a las curiosidades de los muertos". 
resuenan las consecuencias del "Gott ist tot" anunciado por Hegel en su análisis de la Unglückliche Bewusstsein:

Aquella $<s c$. la 'conciencia desdichada'> es, por el contrario, el destino trágico de la certeza de sí mismo, que debe ser en y para sí. Es la conciencia de la pérdida de toda esencialidad en esta certeza de sí y de la pérdida precisamente de este saber de sí - de la substancia como del sí mismo, es el dolor que se expresa en las duras palabras de que Dios ha muerto ${ }^{19}$.

Esta "pérdida" (Verlustes) en tanto "destino trágico" (das tragische Schicksal) es la pérdida del sentido (esto es, de la "certeza de sí", Gewißheit seiner) de un mundo que ha muerto junto con Dios ${ }^{20}$. Asimismo con tono crítico Michel de Certeau (19251986) sostiene:

El pasado nos resulta ficción del presente; lo mismo pasa en todo trabajo historiográfico verdadero. La explicación del pasado nunca deja de marcar la distinción entre el aparato explicativo, que es presente, y el material explicado: los documentos que se refieren a las curiosidades de los muertos ${ }^{21}$.

Por otra parte, invertir la relación entre subjetividad y objetividad, es decir, colocar el tiempo histórico en el plano subjetivo, no resuelve la cuestión. Ello queda manifiesto en la crítica de Heidegger a Jean-Paul Sartre (1905-1980): "La inversión de una frase metafísica sigue siendo una frase metafísica" ${ }^{22}$. En esta misma línea de pensamiento, De Certeau, por ejemplo, considera que las críticas al cientificismo realizadas por Raymond Aron (1905-1983) al intentar disolver el objeto y restituir el lugar del sujeto caían en un mito similar al del objetivismo, en tanto suponen una autonomía de la ideología como orden de ideas que se apartan de la práctica histórica ${ }^{23}$. Por ello, propuestas como la de Halbwachs que plantean una recuperación de "lo histórico" de la memoria - entendido como expresión de una experiencia subjetiva del tiempo - no resuelven la cuestión. Ello se debe a que estos no logran superar la determinación cientificista moderna, ya que se desplazan en el horizonte abierto por la dialéctica sujeto-objeto y se mantienen dentro de sus límites.

\subsection{La temporalidad de lo histórico más allá de la dialéctica sujeto-objeto}

Abordar lo histórico al modo de la cientificidad moderna - esto es, en el marco de la dialéctica sujeto-objeto - como régimen de visibilidad nos lleva a "retirar" ciertas formas de experiencia histórica del plano de "lo visible" como contenido histórico. Sin embargo, podemos afirmar, "transponiendo"24 a Jacques Derrida (1930-2004)

19 G. W. F. Hegel, La fenomenología del espíritu, Fondo de Cultura Económica, México, 2017, p. 435.

20 Cf. Antonio Escohotado, La conciencia infeliz. Ensayo sobre la filosofía de la religión en Hegel, Revista de Occidente, Madrid, 1972.

21 De Certeau, La escritura de la historia, p. 23.

22 Martin Heidegger, "Carta sobre el 'Humanismo"” [1946], en Hitos, Madrid, Alianza, 2001, p. 270.

23 De Certeau, La escritura de la historia, pp. 69-71. Esto lo acercaría a los problemas propios de la historia de las ideas o de los tipos-ideales weberianos.

24 Utilizamos el término "trasposición” en el sentido otorgado por Auguste Diès (1875-1958), quien, aplicándolo 
— quien retoma el planteo heideggeriano de der Entzug des Seyns ("la retirada del ser")-, que la retirada del discurso histórico científicamente establecido por la modernidad también se re-tira, es decir retorna, al reinscribirse "de otro modo" en el discurso histórico ${ }^{25}$. La retirada de la presencia y de la representación científica moderna, en tanto discurso que se despliega en el ámbito de la objetividad trascendente del tiempo, destituye de sí todo recurso a la inmanencia, es decir, la interioridad de la experiencia del tiempo. Por ello, la historiografía - entendida como forma científica del discurso histórico - retira ciertas formas de "experiencia histórica" del espacio de "lo histórico" — es decir, las desplaza del ámbito de "lo visible" — y se presenta a sí misma como una serie discursivamente entrelazada en la que se retiene lo sucedido y se vuelve a presentar (re-presenta) el pasado "en" el discurso.

La retirada, sin embargo, de acuerdo con la tematización derrideana, no solo se retira en cuanto aquello que "ya no está ahí", sino que esta retirada implica un doble movimiento en el cual lo que se retira (retrait) no desaparece sin dejar huellas (traces) - es decir, se lo re-traza (re-trait) como una cuestión que debe postularse otra vez, un giro (tour) más, un trazo suplementario (trait supplémentaire) que se deja en el texto- . En este sentido la retirada permite el retorno en tanto esta desborda los límites de la presencia ${ }^{26}$. Por lo tanto, en nuestro caso la escritura de la historia es la huella (trace) de ese trazo (trait) que se retira (retrait). Pensar la escritura como huella es trascender la pretensión de la escritura científica que sostiene el discurso sobre la base de la "presencia" y la "representación", en tanto las huellas nunca se instalan como presencia plena de sentido, sino que se repiten diferenciándose de sí mismas, apareciendo sobre el fondo de la desaparición:

La huella, donde se enmarca la relación con lo otro, articula su posibilidad sobre todo en el campo del ente, que la metafísica ha determinado como ente-presente a partir del movimiento ocultado de la huella...Pero el movimiento de la huella está necesariamente ocultado, se produce como ocultación de sín $^{27}$.

\section{En este sentido sostenía De Certeau:}

La historiografía no puede pensarse en los términos de una oposición o de una adecuación entre un sujeto y un objeto; eso solo sería el juego de la ficción que ha construido ${ }^{28}$.

Por ello, "hacer historia" en el marco establecido por la dialéctica sujeto-objeto sería equiparar la escritura histórica con la huella $\mathrm{a}^{29} \mathrm{y}$, por tanto, superponer en

\footnotetext{
al caso de la utilización platónica de los conceptos órficos, la considera un trasladar unos conceptos para integrarlos en un pensamiento distinto que los adapta y transforma en un nuevo contexto. Cf. Auguste Diès, Autour de Platon, 2 vols., Gabriel Beauchesne, Paris, 1927, p. 444.

25 Jacques Derrida, "La retirada de la metáfora": Cuaderno gris, n. ${ }^{\circ} 2$ (1997), p. 222.

26 Cf. ibid., p. 210-211.

27 Jacques Derrida, De la gramatología, Siglo XXI, Buenos Aires, 2005, p. 82.

28 De Certeau, La escritura de la historia, p. 24.

29 "Me parece que en Occidente, desde hace cuatro siglos, 'hacer historia' nos lleva siempre a la escritura". Ibid., p. 19. "El texto de la historia, siempre sujeto a revisión, duplica el obrar como si fuera su huella y su interrogante. Apoyado sobre lo que el mismo no es —la agitación de una sociedad, pero también la práctica científica en sí misma-, arriesga el enunciado de un sentido que se combina simbólicamente con el hacer. No sustituye a la praxis social, pero es su testigo frágil y su crítica necesaria”. Ibid., p. 64.
} 
un mismo plano lo conocido y lo implicado en el discurso histórico ${ }^{30}$ tomando por "real" los "efectos de realidad" 31 producidos por el propio discurso ${ }^{32}$. Sin embargo, superar estas consecuencias "nos conduce de la práctica al texto"33, esto es, del "hacer historia" a la escritura de la historia. De manera que:

La representación de la escritura es "plena": llena o tapa las lagunas que constituyen, por el contrario, el principio mismo de la investigación, siempre aguijoneada por la carencia. Dicho de otro modo, por medio de un conjunto de figuras, de relatos y de nombres propios, la escritura vuelve presente, representa lo que la práctica capta como su límite, como excepción o como diferencia, como pasado ${ }^{34}$.

Esta "plenitud", para De Certeau, surge como "efecto de la escritura", no hay nada en las fuentes ni en la historia como práctica que determine su modo de organización, ni su disposición temporal bajo la forma de la sucesión cronológica ${ }^{35}$. La escritura de la historia constituye ese "trazo suplementario" (trait supplementaire) tematizado por Derrida, aquello que desborda la presencia y en la cual el historiador se inscribe al escribir historia. De modo que dicha "plenitud" se presenta como la marca de la inscripción del historiador por medio de la escritura ${ }^{36}$. Por ello, se produce así una suerte de "desubstancialización metafísica” de la historia, debido a que

30 "[L]a situación de la historiografía nos presenta la interrogación sobre lo real en dos posiciones muy diferentes en el proceso científico; lo real como conocido (lo que el historiador estudia, comprende o "resucita" en una sociedad pasada) y lo real como implicado por la operación científica (la sociedad actual a la que se refieren la problemática del historiador, sus procedimientos, sus modos de comprensión y finalmente una práctica del sentido). Por una parte, lo real es el resultado del análisis, y por otra, es su postulado". Ibid., p. 51.

31 Aquí De Certeau retoma la argumentación de Roland Barthes (1915-1980) para quien “los 'hechos' de que habla la historia funcionan como indicadores" (ibid., p. 57), llamando "efecto de lo real" al "artificio del discurso historiográfico, que consiste en ocultar bajo la ficción de un 'realismo', una manera, necesariamente interna al lenguaje, de plantear un discurso. 'El discurso histórico no sigue a lo real, únicamente lo significa al no dejar de repetir así pasó, sin que esta aserción pueda ser nunca otra cosa sino el revés significado de toda narración histórica'. [R. Barthes, "Le discours de l'histoire": Social Science Information, vol. VI, n. ${ }^{\circ} 4$ (1967), p. 65]”. Ibid., p. 58. Sin embargo, De Certeau trasciende la posición de Barthes al considerar que el "efecto de realidad" no es un elemente inmanente al discurso, propio del sistema de significaciones, sino un resultado de la labor historiográfica, esto es, de una práctica.

32 " $[\mathrm{P}]$ odemos notar que esta última huella de un ontologismo del lenguaje, tan frecuente en historia, tiene por consecuencia el hecho de suponer que este reparto en "dimensiones" posee una validez universal y constante... El historiador tiene que pasar por esto: no existe un punto de vista universal. Sino que este referente proviene también de su operación. No está más cerca de lo real, aun cuando sea la condición de un análisis que saca de los materiales un conocimiento real, aunque relativo a un sistema de interpretación". De Certeau, La escritura de la historia, p. 126.

33 De Certeau, La escritura de la historia, p. 101.

34 Ibid. p. 102.

35 Reinhardt Koselleck comparte esta concepción de la periodización histórica como una forma moderna de temporalizar los diferentes estratos temporales, ver: Koselleck, Zeitschichten, pp. 19-26; Helge Jordheim, "Against Periodization: Koselleck's Theory of Multiple Temporalities": History and Theory, vol. 51, n. ${ }^{\circ} 6$ (2012), pp. 151-171. Cf. Hayden White, "El valor de la narrativa en la representación de la realidad”, pp. 17-39; David Carr, Time, Narrative and History, Indiana University Press, Bloomintong, 1991, pp. 45-72.

36 Las discusiones sobre las posibilidades que se derivan como consecuencia de estas lecturas giran en torno a o bien asumir el discurso histórico como representación y, por ende, como horizonte último que hace posible su configuración ("representacionistas"), o bien elaborar estrategias discursivas que tiendan a superar la función representativa ("no-representacionistas"). Cf. Jouni-Matti Kuukkanen, "Representationalism and Non-representationalism in Historiography": Journal of the Philosophy of History, vol. 7, n. 3 (2013), pp. 453-479; Zeleňák, "Two Versions of a Constructivist View of Historical Work", pp. 213-224. 
ella es desligada de los presupuestos de "continuidad" y "ruptura" como elementos intrínsecos a los fenómenos, colocando en primer plano la práctica mediante la cual es producida. No obstante, esta comprensión de la temporalidad histórica no implica una negación de la historia como práctica científica, tal como podría derivarse de un narrativismo radical ${ }^{37}$, sino, por el contrario, una "crítica" en el sentido kantiano de establecimiento de límites sobre qué y cómo se puede conocer en el plano del discurso histórico.

\section{Temporalización de los conceptos y pensamiento político}

En el caso del estudio del pensamiento político, este se ha visto renovado a partir de la segunda mitad del siglo veinte. En el ámbito anglosajón los trabajos de Leo Strauss (1899-1973), Hannah Arendt (1906-1975), John Rawls (1921-2002), etc., han contribuido teóricamente a dicha rehabilitación. En este marco intelectual se ha producido una relectura de los clásicos del pensamiento político (la tradición contractualista por Rawls, los clásicos antiguos por Arendt, el platonismo por Strauss) ${ }^{38}$. Sin embargo, en sincronía con este renovado interés teórico se han revisado los principios hermenéuticos a partir de los cuales se estudia el pensamiento político. La "nueva historia intelectual", en el horizonte del giro lingüístico iniciado por las fi-

37 Para críticas al narrativismo ver: Joyce Appleby, Lynn Hunt y Margaret Jacob, La verdad sobre la historia, Andrés Bello, Santiago de Chile, 1999; David Carr, "Narrative and the Real World: An Argument for Continuity": History and Theory, vol. 25, n. 2 (1986), pp. 117-131; Chris Lorenz, "Historical Knowledge and Historical Reality: A Plea for 'Internal Realism"”: History and Theory, vol. 33, n. 3 (1994), pp. 297-327; Chris Lorenz, "Can Histories Be True?: Narrativism, Positivism and the "Metaphorical Turn"": History and Theory, vol. 37, n." 3 (1998), pp. 309-329; Christopher Behan McCullagh, Justifying Historical Descriptions, Cambridge University Press, Cambridge, 1984; Christopher Behan McCullagh, The Truth of History, Routledge, New York, 1998; Bryan D. Palmer, Descent into Discourse, Temple University Press, Philadelphia, 1990; Eelco Runia, "Presence": History and Theory, vol. 45, n. ${ }^{\circ} 1$ (2006), pp. 1-29; Eelco Runia , "Spots of Time": History and Theory, vol. 45, n. 3 (2006), pp. 305-316; José Sazbón, "La devaluación formalista de la historia", en Ezequiel Adamovsky (comp.), Historia y sentido, El Cielo por Asalto, Buenos Aires, 2001; Verónica Tozzi, "La 'reconstrucción histórica'. Acerca de los supuestos epistemológicos de la explicación y narración historiográfica": Revista de filosofia, vol. 22, n. ${ }^{\circ} 1$ (1996), pp. 55-68; Verónica Tozzi , "El relato histórico: ¿hipótesis o ficción? Críticas al 'narrativismo imposicionalista' de Hayden White”: Análisis Filosófico, vol. 17, n. ${ }^{\circ} 1$ (1997), pp. 75-93; Verónica Tozzi, "Historización, contextualización y perspectiva", en Eduardo Sota y Luis Urtubey, Epistemología e Historia de la Ciencia (Selección de trabajos de las IX Jornadas), vol. 5, n. ${ }^{\circ}$ (1998), pp. 494-501; Perez Zagorin, "Historiography and Postmodernism: Reconsiderations": History and Theory, vol. 29, n. ${ }^{\circ} 3$ (1990), pp. 275-296; Perez Zagorin, "History, the Referent and Narrative: Reflections on Postmodernism Now": History and Theory, vol. 38, n. ${ }^{\circ} 1$ (1999), pp. 1-24; John Zammito, “Ankersmit and Historical Representation”: History and Theory, vol. 44, n. ${ }^{\circ} 2$ (2005), pp. 155-181.

38 Ver Leo Strauss, La persecución y el arte de escribir, Amorrortu, Buenos Aires, 2009; Leo Strauss, Derecho natural e historia, Prometeo, Buenos Aires, 2013; Leo Strauss, The Argument and Action of Plato's Laws, University of Chicago Press, Chicago, 1975; Hannah Arendt, La condición humana, Paidós, Buenos Aires, 2005; Hannah Arendt, Sobre la revolución, Alianza, Madrid, 2013; Hannah Arendt, La vida del espíritu, Paidós, Barcelona, 2002; John Rawls, Teoría de la justicia, Fondo de Cultura Económica, México, 1995; John Rawls, Liberalismo político, Crítica, Barcelona, 1996). Si bien Strauss y Arendt son de origen germano, ejercieron gran influencia en el ámbito anglosajón debido a su exilio y docencia en Estados Unidos, cf. Martin Jay, Exilios permanentes. Ensayos sobre la migración intelectual alemana en Estados Unidos, El cuenco de Plata, Buenos Aires, 2017. Para un panorama general sobre la amplitud de las discusiones suscitadas a partir de dicha "rehabilitación”, ver Derek Matravers y Jon Pike (eds.), Debates in Contemporary Political Philosophy: An Anthology, Routledge, London, New York, 2003. 
losofías de Ludwig Wittgenstein (1889-1951) y John Langshaw Austin (1911-1960) junto con una gran influencia de la perspectiva histórica de Robin G. Collingwood (1889-1943 $)^{39}$, se ha propuesto recuperar el carácter "histórico" del pensamiento político, pero desde una nueva perspectiva ${ }^{40}$ — esto es, dejando de lado el criterio de "lo histórico" del pensamiento como sucesión temporal de ideas que se articulan entre sí, así como las perspectivas que remiten al "contexto" como elemento externo al pensamiento y, por tanto, epifenómeno derivado de "la realidad" material— ${ }^{41}$. Sin embargo, este renovado interés por el acceso al pensamiento político no es exclusivo del ámbito anglosajón; en el ámbito continental también se pueden observar esfuerzos por actualizar el estudio histórico del pensamiento político ${ }^{42}$. En el caso germano como respuesta a la Ideenlehre de raíz neokantiana, mientras que en Italia contra la recepción de la historia constitucional (Verfassungsgeschischte) de origen germano, así como en el ámbito francófono contra la histoire des doctrines. En el caso hispanoparlante la renovación del estudio del pensamiento político se ha llevado a cabo de ambos lados del Atlántico y se ha desplegado en varias direcciones: trabajos de recepción de la Begriffsgeschichte ${ }^{43}$, estudios monográficos dedicados a conceptos políticos ${ }^{44}$, así como estudios sobre la formación del pensamiento político

39 Cf. Ludwig Wittgenstein, Investigaciones filosóficas, Crítica, Barcelona, 2004; John Austin, Cómo hacer cosas con palabras. Palabras y acciones, Paidós, Barcelona, 1990; Robin G. Collingwood, La idea de la historia, Fondo de Cultura Económica, México, 1965; Robin G. Collingwood, Una autobiografía, Fondo de Cultura Económica, México, 1953.

40 Sobre esta cuestión ver los trabajos seminales de la renovación producida por la "Cambridge School": John Greville Agard Pocock, "The History of Political Thought: A Metodological Inquiry”, en Peter Laslett y W. G. Runciman (eds.), Philosophy, Politics and Society, Blackwell, Oxford, 1962, pp. 183-202; John Dunn, "The Identity of the History of Ideas": Philosophy, vol. 43, n. 164 (1968), pp. 85-104; Quentin Skinner, "Meaning and Understanding in the History of Ideas": History and Theory, vol. 8, n. 1 (1969), pp. 3-53. Cf. David Boucher, Texts in Context. Revisionist Methods for Studying the History of Ideas, Dordrecht, Boston, Lancaster, 1985; Preston King, "Historical Contextualism. The New Historicism?": History of European Ideas, vol. 21, n. 2 (1995), pp. 209-233; Gary Browning, "Quentin Skinner, the Cambridge School, and Contextualism”, en $A$ History of Modern Political Thought. The Question of Interpretation, Oxford University Press, Oxford, 2016, pp. 67-88.

41 En este marco de renovación, Skinner, por ejemplo, considera el pensamiento como un factor interviniente en el proceso histórico, en tanto se concibe el texto como un "acto-de-habla" (speech-act); es decir, como un tipo de acción. Cf. Quentin Skinner, "Conventions and the Understanding of Speech Acts": The Philosophical Quarterly, vol. 20, n. ${ }^{\circ} 79$ (1970), pp. 118-138.

42 Para la tradición alemana de la Begriffsgeschichte, ver Reinhardt Koselleck, Futuro pasado. Para una semántica de los tiempos históricos, Paidós, Barcelona, 1993; para la recepción italiana de esta escuela ver Giuseppe Duso, La logica del potere: Storia concettuale come filosofia politica, Polimetrica, Monza, 2006; mientras que para el ámbito francés: Pierre Rosanvallon, Para una historia conceptual de lo político, Fondo de Cultura Económica, México, 2003.

43 Cf. Joaquín Abellán, “'Historia de los conceptos' (Begriffsgeschichte) e historia social. A propósito del diccionario Geschichtliche Grundbegriffe", en Santiago Castillo (coord.), La historia social en España. Actualidad y perspectivas, Siglo XXI, Madrid, 1991, pp. 47-63; Joaquín Abellán, "En torno al objeto de la 'Historia de los conceptos' de Reinhart Koselleck”, en Enrique Bocardo Crespo (comp.), El giro conceptual. Cinco ensayos de Quentin Skinner y seis comentarios, Tecnos, Madrid, 2007, pp. 215-248; Faustino Oncina, "Historia conceptual, Histórica y la modernidad velociferina: diagnóstico y pronóstico de Reinhart Koselleck": Isegoría, n. ${ }^{\circ} 29$ (2003), pp. 211-237; Faustino Oncina, 'Necrológica del outsider Reinhart Koselleck: el historiador 'pensante’ y las polémicas de los historiadores": Isegoría, n. 37 (2007), pp. 35-61; José Luis Villacañas y Faustino Oncina, "Introducción", en Reinhart Koselleck y Hans-Georg Gadamer, Histórica y Hermenéutica, Paidós, Barcelona, 1997, pp. 9-54; Elías José Palti, "Koselleck y la idea de Sattelzeit: un debate sobre modernidad y temporalidad”: Ayer, n. ${ }^{\circ} 53$ (2004), pp. 63-74; Elías José Palti, "Reinhart Koselleck: His Concept of the Concept and Neo-Kantianism": Contributions to the History of Concepts, vol. 6, n. ${ }^{\circ} 2$ (2001), pp. 1-20.

44 Ver: Joaquín Abellán, Democracia. Conceptos politicos fundamentales, Alianza, Madrid, 2011. 
iberoamericano ${ }^{45} \mathrm{y}$ de discusión historiográfica con las principales escuelas ${ }^{46}$. Si bien estos desarrollos han ido acompañados de reflexiones teórico-historiográficas para fundamentar su inscripción en el discurso histórico, las discusiones epistemológicas suelen presentarse en menor grado de relevancia en tanto se las subordina a las primeras. Por esta razón, en este apartado nos proponemos poner en primer plano la cuestión epistemológica.

La "revolución teórica" en la historia político-intelectual producida por la convergencia de diversas tradiciones historiográficas, como bien señala Elías José Palti, se caracteriza porque en ellas se lleva a cabo una transformación respecto de la concepción misma de temporalidad aplicada al pensamiento ${ }^{47}$. Aunque estas concepciones no coincidan entre sí, debido a la insularidad de las escuelas, tienen un horizonte común. En este sentido, Jouni-Matti Kuukkanen había señalado la ausencia de una perspectiva interdisciplinaria que abarcara el estudio histórico del pensamiento e integrara las discusiones teóricas desarrolladas y aportadas por las diferentes disciplinas que lo abordan, para lo cual proponía una filosofía de la historia del pensamiento $^{48}$. Ante ello, se puede plantear la misma cuestión para la historia político-intelectual, en general, y para la historia de la teoría política, en particular. De modo que la cuestión de la temporalidad histórica puede ser considerada un eje a partir del cual analizar el vínculo entre historia y pensamiento.

La Begriffsgeschichte de Reinhardt Koselleck asocia la temporalidad al "cambio conceptual". Sin embargo, para ello refuerza la oposición entre texto y contexto, dado que remite el ámbito de la temporalidad histórica a un elemento externo al concepto: el campo de la historia social, de la cual la historia conceptual forma parte ${ }^{49}$. Por ello, para explicar el cambio histórico evoca la historia social como una entidad transhistórica que contiene todo cambio posible, lo cual, para Blumenberg, nos lleva fuera del reino de la Begriffsgeschichte. De modo que, como bien señala Palti, la historia conceptual así concebida carece de una temporalidad histórica propia, dado que remite a la temporalidad establecida por la historia social. Posiblemente esta estrategia teórica por parte de la Begriffsgechichte de Koselleck responda al intento de evitar

45 Cf. Javier Fernández Sebastián y Juan Francisco Fuentes Aragonés (dirs.), Diccionario politico y social del siglo XIX español, Alianza, Madrid, 2002; Javier Fernández Sebastián (coord.), Diccionario politico y social del siglo XX español, Alianza, Madrid, 2008; Javier Fernández Sebastián, "Estado, nación y patria en el lenguaje político del siglo XIX": Revista de historia militar, número extraordinario (2005), pp. 159-220. Para el caso latinoamericano se puede ver: Elías José Palti, La nación como problema. Los historiadores y la "cuestión nacional”, Fondo de Cultura Económica, Buenos Aires, 2002; Elías José Palti, El tiempo de la política: el siglo XIX reconsiderado, Siglo XXI, Buenos Aires, 2007.

${ }^{46}$ Cf. José Luis Villacañas, "Histórica, historia social e historia de los conceptos políticos": Res publica, n. ${ }^{\circ}$ 11-12 (2003), pp. 69-94; Javier Fernández Sebastián, “Textos, conceptos y discursos políticos en perspectiva histórica": Ayer, n. ${ }^{\circ} 53$ (2004), pp. 131-151; Javier Fernández Sebastián, "Historia de los conceptos. Nuevas perspectivas para el estudio de los lenguajes políticos europeos": Ayer, n. ${ }^{\circ} 48$ (2002), pp. 331-372; Elías José Palti, "Temporalidad y refutabilidad de los conceptos políticos": Prismas, n. 9 (2005), pp. 19-34; Elías José Palti, "El retorno del sujeto: subjetividad, historia y contingencia en el pensamiento moderno", en Manuel Cruz Rodríguez y Daniel Brauer, La comprensión del pasado: escritos sobre filosofía de la historia, Herder, Barcelona, 2005, pp. 265-304.

47 Elías J. Palti, “The 'Theoretical Revolution' in Intellectual History: From the History of Political Ideas to the History of Political Languages": History \& Theory, vol. 53, n. 3 (2014), p. 388.

48 Jouni-Matti Kuukkanen, "Toward a Philosophy of the History of Thought": Journal of the Philosophy of History, vol. 3, n. ${ }^{\circ} 1$ (2009), pp. 25-54.

49 Koselleck, Futuro pasado, pp. 124-129; Reinhart Koselleck, Begriffsgeschichten. Studien zur Semantik und Pragmatik der politischen und sozialen Sprache, Frankfurt am Main, Suhrkamp, 2006, pp. 21-30. 
caer tanto en una suerte de "solipsismo de los conceptos" como en el relativismo histórico. Debido al carácter "externo" que asume la temporalidad histórica de la Begriffsgeschichte, el giro pragmático producido por la "Escuela de Cambridge" (Quentin Skinner, John G. A. Pocock) al centrar su análisis en la dimensión performativa del lenguaje, rompe con la separación entre texto y contexto al considerar el texto como speech-act ("acto de habla") y, por tanto, como un elemento integrado en el contexto. De manera que dentro de esta perspectiva la temporalidad histórica remite al "contexto discursivo" inherente a los discursos. Por ello, según esta perspectiva, los cambios conceptuales ocurren cuando los sujetos introducen nuevos significados en los lenguajes disponibles, produciendo un giro en los vocabularios disponibles para los hablantes ${ }^{50}$. Sin embargo, según Palti, si bien esta perspectiva logra explicar los cambios en los significados, no logra dar cuenta de los cambios producidos al nivel de los lenguajes ${ }^{51}$. Por esta razón, los análisis de las condiciones del discurso llevados a cabo por la "Corriente francesa" (Pierre Rosanvallon) remiten a una dimensión que permite comprender los cambios en la forma (esto es, su gramática) ${ }^{52}$. A partir de esta perspectiva, la historia conceptual deja de remitir a los discursos en tanto conjuntos de enunciados y se dirige hacia los dispositivos que los producen. Por ello, no se ocupa de lo que se puede decir, sino del modo de producción de los enunciados, el cual establece los límites de "lo posible". Esto se debe, según esta perspectiva, a la indeterminación semántica de los lenguajes, condición que permite aceptar diversas formas - incluso contradictorias — de articulación. Ello coloca el lenguaje en una dimensión simbólica inherente a las prácticas, en tanto trasciende el plano de las representaciones de "la realidad" y reorienta la mirada hacia la dimensión simbólica en que las representaciones son producidas. Por ello, la temporalidad histórica está caracterizada por la apertura a un horizonte contingente e indeterminado que permite concebir el concepto político como un campo problemático semánticamente abierto.

En lengua española la discusión teórica también ha sido productiva y ha llevado al desarrollo de diversas temáticas vinculadas a esta cuestión. Entre ellos se encuentran los aportes de Javier Fenández Sebastián, quien si bien se ocupa del tema de la temporalidad histórica, al igual que Koselleck, lo aborda principalmente vinculado a la cuestión del "cambio conceptual" 53 . Para este la comprensión del cambio conceptual no solo permite una mejor aproximación al fenómeno del cambio histórico, sino que además nos abre "la posibilidad de concebir modelos de temporalidad distintos del cronotopo en el que estamos instalados y que asumimos como parte del sentido común" 54 . Sin embargo, a diferencia de Koselleck, para Fernández Sebastián la era Moderna presenta una transformación radical en dicha "experiencia de historicidad", en tanto el cambio que se produce no es otra cosa que "el hundimiento de un mundo

${ }_{50}$ Cf. Martin Jay, "La explicación histórica: reflexiones sobre los límites de la contextualización": Prismas, n. ${ }^{\circ}$ 16 (2012), pp. 145-157, señala como límite del "contextualismo" su imposibilidad de pensar los "intellectual events" - es decir, "los raros personajes que son los legisladores intelectuales de su época, podría ser aconsejable refrenarnos de acotar nuestra mirada a los contextos de los cuales emergieron" (ibid., p. 155)_, retomando la noción de événement desarrollada por Claude Romano, El acontecimiento y el mundo, Biblos, Buenos Aires, 2017; Claude Romano, L’Événement et le temps, Presses Universitaires de France, Paris, 1999.

51 Palti, "The 'Theoretical Revolution' in Intellectual History", pp. 392-394.

52 Rosanvallon, Para una historia conceptual de lo político, p. 35.

53 Cf. Fernández Sebastián, "Historia, historiografía, historicidad”, pp. 35-64; Javier Fernández Sebastián, “¿Qué es un diccionario histórico de conceptos políticos?": Anales, n. ${ }^{\circ}$ 7-8 (2004-2005), pp. 223-240.

54 Fernández Sebastián, "Historia, historiografía, historicidad", p. 37. 
—o quizá mejor el ocaso de una concepción del mundo_" "\$5. Por ello, coloca el foco de su análisis en la transformación producida por las revoluciones occidentales, las cuales dan origen a un nuevo modo de cambio conceptual. Estas revoluciones habrían develado la contingencia e historicidad de los conceptos, abriendo la posibilidad de convertirlos en objetos de una historia ${ }^{56}$. De modo que la Modernidad estableció un "nuevo régimen de conceptualidad" que nace en la experiencia de fragilidad, inestabilidad e incertidumbre abierta por las revoluciones. Por otra parte, en el ámbito de los "Estudios latinoamericanos", Elías Palti había propuesto el paso del estudio de las "ideas" al de los "lenguajes políticos" 57 . Para el historiador argentino el estudio histórico de los lenguajes políticos, a diferencia de la historia de las ideas y de las concepciones "débiles" de la historia intelectual, coloca la temporalidad histórica como un elemento intrínseco a los lenguajes y no como derivado de un elemento externo (historia social o contexto discursivo) ${ }^{58}$. En este sentido, Palti retoma la concepción de "lo político" de Rosanvallon, quien considera que ello - es decir, su temporalidad intrínseca - se deriva del hecho de que estos conceptos no se pueden establecer de modo objetivo, por lo cual una "historia conceptual de lo político" solo es posible debido a que dicha indeterminación es la condición misma de "lo político" 59 . Por esta razón, los lenguajes políticos son aquellos en los cuales se establecen las condiciones de contingencia a partir de las cuales todos los conceptos que los componen son índices de problemas, antes que representaciones de entidades objetivas. Los conceptos que conforman los lenguajes políticos son conceptos constitutivamente indecidibles, por lo cual, según Palti, su significado es resultado de un acto contingente por parte de los actores políticos.

Los conceptos políticos, por tanto, a diferencia de otros conceptos, no refieren al plano de la objetividad - esto es, a un plano de entidades estables y definibles-, puesto que nos dirigen a un plano de conflictividad propio de "lo político", por lo cual propongo llamar a dicho plano "objetualidad" ${ }^{60}$. Este plano constituye aquella dimensión en la que se toma la decisión de establecer un objeto - es decir, posicionarlo de manera contingente ${ }^{61}$ - en una situación determinada. Este acto de posicionamiento de un objeto pone de relieve el carácter conflictivo de la situación en la cual se establece, dado que solo se decide la "posición de un objeto" cuando

55 Ibid., p. 40.

56 Ibid., p. 47.

57 Cf. Elías José Palti, “De la historia de 'ideas' a la historia de los 'lenguajes políticos'. Las escuelas recientes de análisis conceptual: el panorama latinoamericano": Anales, n. ${ }^{\circ}$ 7-8 (2004-2005), pp. 63-82.

58 Palti, “The 'Theoretical Revolution' in Intellectual History", pp. 397-399.

59 Cf. Rosanvallon, Para una historia conceptual de lo político, pp. 44-45. Esta perspectiva se sostiene sobre el carácter polémico que asume el "concepto de lo político" en Carl Schmitt, El concepto de lo político, Alianza, Madrid, 2014.

60 El término "objetual" proviene de la tendencia artística iniciada a partir de los ready-mades de Marcel Duchamp (por ejemplo, la obra "Fountain" de 1917) a comienzos del siglo veinte, la cual utiliza objetos "reales" para, luego de una manipulación, decidir sobre ellos la incorporación en un nuevo campo de significación. Esta corriente establece las bases de lo que en la década de 1960 se denominó “arte conceptual”. Cf. Simón Marchán Fiz, Del arte objetual al arte de concepto. Epílogo sobre la sensibilidad posmoderna, Akal, Madrid, 1990; Lucy R. Lippard, Seis años: la desmaterialización del objeto artístico (de 1966 a 1972), Akal, Madrid, 2004; Adolfo Vásquez Rocca, "Arte conceptual y postconceptual. La idea como arte: Duchamp, Beuys, Cage y Fluxus": Nómadas. Revista Crítica de Ciencias Sociales y Jurídicas, vol. 37, n. ${ }^{1}$ (2013), pp. 1-29.

${ }_{61}$ "Posición de objeto" remite al carácter transitorio del objeto en el plano de la objetualidad, a diferencia de la "definición de objetos" en el plano de la objetividad, dado que allí el objeto constituye un significado semánticamente cerrado. 
este se encuentra en una situación de indefinición. Por ello, podemos decir que lo indecidible opera como condición en la cual se instituye la necesidad de posicionar un objeto para poder otorgar sentido al mundo en el cual se despliega una acción, son conceptos que vienen a llenar un vacío de sentido ${ }^{62}$. Por ello, estos "conceptos políticos" se disponen como conceptos de "lo político", en tanto son indicadores del campo problemático en el cual se inscriben. De modo que los conceptos de "lo político" son aquellos sobre los cuales se "hace historia", en el sentido de De Certeau, en tanto es sobre ellos que los agentes político-intelectuales toman posición. Sin embargo, no solo son conceptos sobre los que se toma posición, sino que dicha posición implica establecer un fondo de sentido a partir del cual se toman decisiones para actuar - es decir, le dan sentido a las acciones - . De modo que "lo político" de la teoría se vincula a la acción en un doble sentido, por un lado, es un "acto de habla" (speech-act) en tanto acción que se lleva a cabo para intervenir en un contexto discursivo; mientras que, por otra parte, es el marco de inteligibilidad a partir de la cual la acciones adquieren sentido. Por ello, se puede sostener que la temporalidad de los conceptos políticos opera también en diferentes estratos, por un lado, vinculada a las acciones realizadas por los agentes históricos; pero, por otra parte, a la apertura de posibilidades futuras para la acción, aunque truncas en el plano fáctico.

Entre los dispositivos mediante los cuales esta práctica de "posicionar objetos" se lleva a cabo se encuentra la "teoría". Esta, por su parte, se "hace política" en tanto interviene en la práctica de delimitación de los conceptos, esto es, sobre aquellas representaciones cuya definición está en conflicto. La teoría es "política", por tanto, no porque remita a un conjunto de entidades propias de "la política", sino porque interviene en el campo de disputa en torno a los significados de los conceptos y estos, a su vez, constituyen el horizonte de comprensión que otorga sentido al marco sobre el cual se despliegan las acciones. Por ello, la temporalidad de este tipo de conceptos no se deriva de un elemento externo, sino que es constitutivo de su inteligibilidad. Mientras que la historización de estos conceptos se deriva de las prácticas mediante las cuales son integrados en tramas discursivas. De modo que una "historia de la teoría política" no puede reducirse a la facticidad de un pensamiento "que ha sido", sino que también remite al ámbito de "lo que era posible de ser". Dado que, siguiendo el argumento de Martin Jay a partir de su apropiación del lenguaje de Claude Romano, la temporalidad del pensamiento como "acontecimiento intelectual" lo vincula no solo al sujeto que realiza una acción, sino también al adviniente a quien le acontece.

\section{Historia y politización del pensamiento}

La cuestión de cómo llevar a cabo la construcción de un discurso capaz de dar cuenta de la historia de la teoría política nos remite a un asunto preliminar: la delimitación del fenómeno que será objeto de dicho estudio. El uso del genitivo "de" nos presenta una anfibología. Por una parte, puede indicar que se lleva a cabo el estudio de "una

62 A esta condición remite Esposito cuando retomando la observación de Simone Weil (1909-1943), según la cual el léxico político en su interior se encuentra "vacío", considera que la perspectiva impolítica, al denunciar la carencia que padecen las categorías políticas de la modernidad, consiste en entrar en el campo de disputa en torno al significado que se le atribuye a dicho "vacío". Cf. Roberto Esposito, Diez pensamientos acerca de la política [1993], Fondo de Cultura Económica, México, 2012, p. 12. 
historia propia de la teoría política", esto es, una dimensión o rama específica de la historia que se ocupa de la teoría política, lo cual la coloca como el sujeto portador de un tipo específico de historia (genitivo subjetivo). Mientras que, por otra parte, puede indicar que se hace una "historia acerca de la teoría política", lo cual la coloca como objeto de este discurso histórico (genitivo objetivo). De acuerdo con cómo tomemos el genitivo, por tanto, se definirá el carácter del trabajo a realizar, puesto que ello delimita epistemológicamente nuestro objeto de estudio. En el primer caso - esto es, tomado como genitivo subjetivo - el trabajo realizado formaría parte de una reflexión teórico-historiográfica acerca de la especificidad de una determinada práctica científica en el campo de la historia del pensamiento; mientras que, en el segundo caso - es decir, tomado como genitivo objetivo - el trabajo se definiría como una aproximación científica hacia la teoría política como fenómeno histórico. No obstante, la serie de problemas que esto implica no se resuelven solamente tomando posición respecto de esta cuestión, sino que dependen en cierta medida de una interconexión de posiciones que deben ser establecidas para delimitar nuestro objeto de estudio.

\subsection{Acerca de la unidad conceptual entre "teoría" y "política"}

El término "teoría política" con el cual referimos al objeto de nuestro discurso presenta, a su vez, otra serie de cuestiones a dilucidar para delimitarlo conceptualmente. Este constituye su unidad a partir de la relación entre dos términos: "teoría" y "política". Este hecho implica que el término es una construcción realizada para dar cuenta de un fenómeno configurado por aspectos que no se dan de modo inmediato el uno en el otro, sino que son resultado de un proceso de unificación. Esta unificación puede ser considerada o bien como producto de un movimiento conceptual en el cual uno se deriva del otro, o bien como una construcción discursiva que da cuenta de un campo problemático de interés para el historiador ${ }^{63}$. En el primer caso, a su vez, se nos abren dos posibilidades. Si consideramos que teoría política es un concepto que surge a partir de un proceso de unificación conceptual en un momento histórico dado, entonces habría que pensar una "politización de la teoría". De ello se puede dar cuenta, debido nuevamente al carácter anfibológico del genitivo "de", o bien a partir de un mecanismo en el cual "lo político" se incorpora en el horizonte de comprensión de la teoría, o bien, por el contrario, un movimiento a partir del cual la teoría se patentiza en el horizonte de "lo político". Dicho de otro modo, cabe pensar si "lo político" se torna teoría o si la teoría se hace "política"64. En el segundo caso res-

Estos dos planos con los que se realiza el trabajo del historiador fueron planteados con mayor claridad por Koselleck, Futuro pasado, p. 334.

64 A partir de la distinción entre "la política" y lo "político", marcamos el uso del adjetivo "político/a" de dos maneras, cuando se usa como perteneciente al ámbito de "lo político" se lo señala con el uso de comillas (""), mientras que aplicado al ámbito de "la política" se lo deja sin marca. La diferencia entre lo político y la política, muy arraigada en la tradición intelectual francesa, remite a lo que Oliver Marchant llamó la différence politique (Olivier Marchant, El pensamiento político posfundacional, Fondo de Cultura Económica, Buenos Aires, 2009). Esta conceptualización, dicho brevemente, remite a la política entendida como actividad institucionalizada exclusiva de un grupo profesional y reducido de la sociedad, quienes integran las estructuras y el campo de acción dominado por la preeminencia del Estado; mientras que "lo político" remite a la esfera extra-institucional, es decir, es el espacio donde se configura el poder y en el cual los agentes sociales ejercen influencia por fuera de la práctica profesional de la política. 
pecto de la unificación, si la teoría política surge como construcción discursiva por parte del historiador, entonces esto establece como presupuesto su propia limitación histórico-conceptual, dado que ello implicaría que la teoría política es tematizable a partir de las condiciones conceptuales que se dan en nuestro tiempo y, a su vez, que nos permiten pensarla como objeto de nuestro discurso. Esto quiere decir, entonces, que la teoría solo es política en el mundo moderno debido a que es allí donde se dan las condiciones para pensarla como tal y, por tanto, es en el marco de nuestra modernidad que esta surge como problema y no antes. Sin embargo, la anfibología que implica la "politización de la teoría" nos abre otro camino respecto de este segundo aspecto problemático, dado que pone en evidencia que la teoría política no es un fenómeno exclusivo de la modernidad, sino que lo que surge tras nuestra pregunta por ella es la diversidad de modos en que esta se hace manifiesta. Respecto de la politización de los conceptos, afirma Koselleck que el Sattelzeit delimita el comienzo de "lo moderno":

Recién con el fracaso de las constantes naturales de la vieja experiencia del tiempo histórico, en otras palabras, con la liberación del progreso, surge una gran cantidad de nuevas preguntas ${ }^{65}$.

De modo que la nueva experiencia del tiempo histórico (historischen Zeiterfahrung) permite la formulación de nuevas preguntas. No obstante, esto no significa que la novedad en la forma de preguntar por la ciencia histórica (Geschichtswissenchaft) implique necesariamente una novedad respecto de todos los referentes a los que este preguntar remite ${ }^{66}$. Por ello, cabría determinar bajo qué condiciones la teoría política surge como forma exclusiva de la modernidad y bajo qué otras como fenómeno posible de ser pensado en otros momentos históricos.

Algunos de los aspectos desarrollados por Reinhardt Koselleck nos permitirán dilucidar esta cuestión. Los trabajos de este se enmarcan en el universo problemático del ámbito intelectual alemán del siglo veinte, el cual se desarrolla luego del debate filosófico entre Carl Schmitt (1888-1985), Karl Löwith (1897-1973), Erik Peterson (1890-1960) y Hans Blumenberg (1920-1996) acerca de la legitimación de la modernidad a partir del concepto de Säkularisierung ${ }^{67}$. En este marco él parte de una heuristischer Vorgrif según la cual el período que se da entre 1750 y 1850 constituye un Sattelzeit, esto es, un período en el que cambia todo el conjunto de conceptos del campo político-social, dado que "los significados originales se transforman en su avance hacia nuestro presente" 68 . Este fenómeno, según Koselleck, se debe a que en la modernidad se produce un nuevo desplazamiento de la coordinación entre "experiencia" (Erfahrung) y "expectativa" (Erwartung), las cuales son "condición de toda historia posible" (Bedingung möglicher Geschichten), en tanto "son dos categorías

${ }_{65}$ Reinhardt Koselleck, "Sobre la necesidad teórica de la ciencia histórica": Prismas, n. ${ }^{\circ} 14$ (2010), p. 141.

66 Cf. ibid., p. 140.

67 Carl Schmitt, Teología política, Trotta, Madrid, 2009; Karl Löwith, Historia del mundo y salvación, Buenos Aires, Katz, 2007; Erik Peterson, El monoteismo como problema político, Trotta, Madrid, 1999; Hans Blumemberg, La legitimidad de la Edad Moderna, Pre-Textos, Valencia, 2008. Cf. Hermann Lübbe, Säkularisierung: Geschischte eines Ideenpolitischen Begriffs [1965], Verlag Karl Alber Freibutg, München, 2003.

68 Reinhardt Koselleck, "Introducción al Diccionario histórico de conceptos político-sociales básicos en lengua alemana" [1972], trad. de Luis Fernández Torres: Anthropos, n. ${ }^{\circ} 233$ (2009), p. 95. 
adecuadas para tematizar el tiempo histórico por entrecruzar el pasado y el futuro"69. Por ello, el modo de articularse que se produce hacia este período da lugar a una forma de experiencia histórica propia de la modernidad. Ello, según Koselleck, se debe a que "[s]e trata de categorías del conocimiento que ayudan a fundamentar la posibilidad de una historia" ${ }^{70}$, en tanto "[1] as condiciones de posibilidad de la histo-

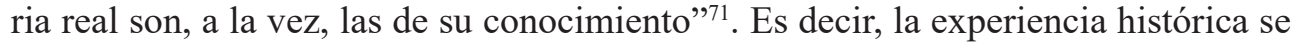
organiza temporalmente a partir del modo en que se articulan Erfahrung y Erwartung, dado que son categorías que hacen posible que el conocimiento histórico pueda ser expresado bajo la forma de una historia (Geschichte). Por ello que toda "historia real (efectiva)" (wirklicher Geschichte) solo es posible a partir de las categorías que nos permiten su conocimiento (Erkenntnis) ${ }^{72}$.

De acuerdo con Koselleck una de las novedades introducidas por este Sattelzeit - es decir, lo que nos permite comprender la "modernidad" (Neuzeit) como "nuevo tiempo" (neue Zeit) - es la temporalización (Verzeitlichtung) de los conceptos políticos a partir de una nueva articulación entre "experiencia" (Erfahrung) y "expectativa" (Erwartung) ${ }^{73}$. Esto implica que en la modernidad se produce una transformación radical respecto de las formas en que se constituye la experiencia del tiempo histórico (historischen Zeiterfahrung), lo cual habría derivado también en la posibilidad de desarrollar nuevas prácticas. En este sentido sostiene Koselleck que gracias a Erfahrung y Erwartung es posible "descubrir" (aufzuspüren) el tiempo histórico, "pues enriquecidas en su contenido, dirigen las unidades concretas de acción en la ejecución del movimiento social o político"74. Esto ocurriría, por ejemplo, con el concepto de "revolución":

El concepto lleva al conocimiento y, simultáneamente, señala la acción que realizar. En eso consiste su modernidad. Es un concepto reflexivo que agrupa las condiciones de la acción política con el análisis del conocimiento histórico ${ }^{75}$.

Por ello, el conocimiento que hace posible el concepto en su apertura temporal hacia el futuro - gracias a la nueva articulación entre Erfahrung y Erwartung que se produce con la modernidad - permite pensar y, por tanto, establecer las condiciones (Bedingungen) que permiten proyectar acciones en ese futuro (handlungsanweisend).

De acuerdo con estos análisis, lo que produce la modernidad no es la emergencia de "la politización" como tal, sino de nuevas formas de "politización de los conceptos" (Politisierung der Begriffe) vinculadas a "conceptos dinámico-temporales" (Bewegungsbegriffe) surgidos a partir del proceso de historización del tiempo ${ }^{76}$. De

Koselleck, Futuro pasado, p. 337.

Ibid., p. 335.

Ibid., p. 336.

72 Cf. Reinhardt Koselleck, "El siglo XVIII como comienzo de la Edad Moderna", en Modernidad, culto a la muerte y memoria nacional, Centro de Estudios Políticos, Madrid, 2011, pp. 12-17. Para una presentación de las características principales de la Sattelzeit como clave para entender el sentido de la modernidad según Koselleck, ver Palti, "Koselleck y la idea de Sattelzeit", pp. 64-68.

73 Cf. Koselleck, Futuro pasado, pp. 342 y 211.

74 Ibid., p. 337.

75 Reinhardt Koselleck, Historias de conceptos. Estudios sobre semántica y pragmática del lenguaje politico y social, Trotta, Madrid, 2012, p. 162.

76 Cf. Koselleck, "Über die Theoriebedürtigkeit", p. 303; Reinhart Koselleck "Introducción al Diccionario históri- 
modo que "la politización de la teoría" como objeto de un discurso histórico no establece la determinación de este concepto como forma exclusiva de la experiencia moderna para establecer las condiciones de su historicidad, sino que señala el hecho de que el proceso de historización del mismo se deriva de nuestra forma moderna de pensar los fenómenos. Esto quiere decir que pensar históricamente la teoría política como un fenómeno exclusivamente moderno: en lugar de restituir su historicidad como fenómeno y como concepto para evitar el anacronismo - tal y como proponen las perspectivas más rígidas — , produce lo contrario - es decir, lo reduce a formas de inteligibilidad moderna ligadas al proceso de temporalización-.

El punto de partida problemático en torno a la unificación de "teoría" y "política" que implica el concepto nos lleva a establecer una hipótesis de trabajo, según la cual: si bien la capacidad de pensar la "politización de la teoría" como fenómeno histórico es posible gracias a la condiciones conceptuales de la modernidad, ello pone de manifiesto que la modernidad establece las condiciones de historicidad para su inteligibilidad como proceso, pero hace patente, además, que es el discurso histórico el que establece la "historización" del fenómeno. De modo que nuestro objetivo como historiadores de la teoría política será realizar el camino inverso, una suerte de "deconstrucción de la historización", para determinar las diversas formas de establecimiento de la historicidad que se dan en "la politización de la teoría", lo cual nos permite establecer su "especificidad histórica" para, a partir de allí, producir un discurso historiográfico que nos permita restituir una historización que sea capaz de establecer la historicidad del fenómeno. La historicidad del fenómeno, de acuerdo con esto, sería el resultado de un proceso de "establecimiento" en tanto el estatuto histórico del objeto es resultado de la historización, lo cual se da a partir de las categorías de comprensión científica que la modernidad desarrolla a partir de la transformación del mundo de la vida; de modo que su historicidad no remite a una propiedad ontológicamente previa al discurso historiográfico, puesto que ello implicaría la proyección del carácter de "entidad histórica" a los "efectos" del propio discurso historiográfico ${ }^{77}$.

Por todo ello, la perspectiva en torno a la unidad conceptual entre "teoría" y "política" nos abre el juego antes que cerrarlo. Dado que el carácter "histórico" a partir del cual se lleva a cabo nos permite plantear que la historia científica responde a una forma propia de la experiencia moderna de conceptualizar el mundo, pero que lleva en sí misma su capacidad de superación. Ello nos abre, por tanto, dos caminos intrínsecamente irresolubles entre sí: $(a)$ el pensamiento histórico es un modo moderno de ver el mundo y, por ende, queda sujeto en las condiciones de enunciación que él establece; $(b)$ reconocer el alcance y los límites de esta como forma moderna de ver el mundo establece las condiciones para su superación.

co de conceptos político-sociales básicos en lengua alemana", pp. 96-97; Reinhart Koselleck, "Geschichte, Historie", en Geschichtliche Grundbegriffe. Historisches Lexikon zur politisch-sozialen Sprache in Deutschland, ed. de Otto Brunner, Werner Conze y Reinhart Koselleck, Klett-Cotta, Stuttgart, 1975, pp. 666-668; Reinhart Koselleck, "The Temporalisation of Concepts": Finnish Yearbook of Political Thought, vol. 1 (1997), pp. 16-19; Reinhart Koselleck, "Begriffliche Innovationen der Aufklärungssprache” [2001], en Begriffsgeschichten, pp. 328-339, así como el análisis de los sustantivos 'Fortschritt' y 'Niedergang' como conceptos dinámicos propios de la modernidad, ver Reinhart Koselleck, “'Fortschritt' und 'Niedergang' - Nachtrag zur Geschichte zweier Begriffe" [1980], en Begriffsgeschichten, pp. 171-175.

77 Sobre este punto vide supra nota 61 acerca de la diferencia entre los procesos de "posición de objeto" y "definición de objeto". 


\subsection{Acerca del carácter "político" de la teoría}

La problemática de la unificación conceptual entre "teoría" y "política" nos remite además, como planteamos anteriormente, a la siguiente cuestión: ¿"lo político" se incorpora en el horizonte de comprensión de la teoría, o bien la teoría se patentiza en el horizonte de "lo político"? Esta formulación del problema tiene que ver con lo que Oliver Marchart llamó la "différence politique"; sin embargo, esto no nos impide dejar abierto "el libre juego" (das freie Spiel) $)^{78}$ de la cuestión. Nos encontramos aquí con dos formas posibles de articulación entre "teoría" y "política", donde la diferencia radica en quién ejerce primacía sobre el otro y cómo se establece la inscripción de uno en el otro para producir la unificación. Sin embargo, esto no implica que la forma en que se produce la articulación sea una forma cerrada, ante lo cual podemos proponer que ello se debe al hecho de que dicha articulación también se produce de manera histórica. Si aceptamos con Koselleck que lo "nuevo" (das neue) de "la modernidad" (Neuzeit) radica en la incorporación de una forma de temporalización de los conceptos políticos bajo una forma de inteligibilidad "histórica" (geschichtliche) que se construye sobre la primacía a largo plazo de la expectativa hacia el futuro, debemos aceptar que en la modernidad los conceptos se tornan políticos en tanto se enmarcan en esta nueva dimensión histórica abierta por la experiencia moderna. Por ello, resta establecer, para el caso de la teoría política, cuál es la forma histórica en que se articula su unificación.

Resulta de suma utilidad, en este último punto, el artículo de Koselleck donde analiza la semántica del término "revolución" en tanto "concepto fundamental" (Grundbegriff) de la modernidad, esto es, como nuevo aglutinante de experiencias y expectativas ${ }^{79}$. Sin embargo, esto no implica que el concepto como tal sea de uso exclusivo de la modernidad, sino, como sostiene Koselleck, lo es su "uso estrechamente político del término" (engere politische Wortgebrauch) ${ }^{80}$. Ahora bien, esto podría entenderse como significando o bien que lo propio de la modernidad es haber realizado un "uso político" del término o bien que la modernidad introduce otra for$m a$ de "usar políticamente" el término. La clave para comprender la afirmación de Koselleck está en el adjetivo eng ("estrecho", "ceñido", "restringido" > engere: "estrechamente"), con ello señala que la novedad introducida por la modernidad no es su "uso político", sino el haberlo restringido a ese uso estrecho otorgándole en este caso nuevos significados ${ }^{81}$. Esto quiere decir que la politización de los términos no

78 Cf. Immanuel Kant, Kritik der Urteilkraft [1793], en Immanuel Kants Werke, ed. de Ernst Cassirer et al., Verlegt bei Bruno Cassirer, Berlin, 1914, III, pp. 233-568.

79 Cf. Koselleck, Historias de conceptos, p. 162.

80 Cf. ibidem.

${ }_{81}$ Koselleck acentúa este aspecto frente a la Verfassungsgeschichte elaborada por Otto Brunner, Land und Herrschaft. Grundfragen der territorialen Verfassungsgeschichte Österreichs im Mittelalter [1939], Wissenschaftliche Buchgesellschaft, Darmstadt, 1984. Si bien se podría considerar que cuando Koselleck en "Introducción al Diccionario histórico de conceptos político-sociales básicos en lengua alemana", pp. 8-9, afirma que "el lexicón está orientado al presente en la medida en que tiene como tema la compresión lingüística del mundo moderno, su proceso de toma de conciencia [Bewusstwerdungund Bewusstmachung], conciencia a la que se llega mediante conceptos, que también son los nuestros", estaría restringiendo la especificidad de los "conceptos políticos" a la modernidad; esta afirmación, en cambio, se realiza luego de sostener que: "El aspecto central de las investigaciones son los conceptos de la 'Modernidad', que incluyen más significados que solo los 'modernos'. Precisamente se tratarán las superposiciones y los desplazamientos de significados 'modernos' y 'antiguos'. Por eso se harán referencias a la Antigüedad, a la Edad Media, al Renacimiento, a la Reforma y al Humanismo, en tanto en cuanto la historia terminológica de los conceptos proceda de esas épocas". 
es una propiedad de la modernidad, sino que lo es la forma de politización articulada en torno a una experiencia de temporalidad concebida como "histórica".

En la experiencia pre-moderna de los conceptos, por tanto, su politización responde a "usos políticos" de los términos en los cuales no interviene necesariamente la "temporalidad histórica" como su forma de inteligibilidad, sino que la politización remite a la incorporación de la teoría en el ámbito de la conflictividad propia de "lo político". Por ello podemos afirmar que el adjetivo "político" remite a todo aquello que se inscribe en dicho ámbito de conflictividad, mientras que lo propio de la modernidad habría consistido en pensarlo de forma "histórica" articulada en torno a la figura del Estado. Por ello en la modernidad el adjetivo remite a "lo propio del Estado", dada la preeminencia de este como forma totalizante de la política.

\section{Consideraciones finales}

El presente trabajo tenía como objetivo pensar "la temporalidad histórica de la teoría política". Para ello se llevó a cabo una reflexión teórica sobre los problemas y perspectivas que intervienen a la hora de proponer una "historia de la teoría política". Estas reflexiones nos han permitido dar cuenta de las falencias que implica una aproximación "histórica" que deje de lado la discusión respecto de las condiciones propias del discurso histórico: la producción de un discurso que presupone "lo histórico" como algo dado objetivamente en todo objeto, como si fuera una suerte de elemento que se da en simultáneo con la temporalidad "natural". Por ello, el análisis de las diversas perspectivas que abordan la cuestión de la temporalidad histórica nos ha permitido abrir el panorama de la cuestión y puso de relieve la necesidad de superar la dialéctica sujeto-objeto como clave para su comprensión. Mientras que pone de relieve la importancia de los procesos de historización. Asimismo, dado que la teoría política es una práctica intelectual que se lleva a cabo mediante conceptos, discutir los alcances de su temporalización nos permitió establecer la indeterminación de sus conceptos como el elemento que carga con su historicidad en tanto indicador de la situación conflictiva en la que emerge. Finalmente, a partir de estos análisis hemos discutido acerca del vínculo entre historia y politización del pensamiento conceptual. Allí hemos puesto de relieve que la unidad entre los términos "teoría" y "política" que conforman el concepto de "teoría política" presenta un carácter problemático, en tanto habría sido resultado de un "proceso de unificación conceptual"; no obstante, se ha manifestado que, debido a la naturaleza de los conceptos desarrollados en ella, en dicho proceso intervino, además, otro de "politización".

\section{Referencias bibliográficas}

Abellán, Joaquín, “'Historia de los conceptos'(Begriffsgeschichte) e historia social. A propósito del diccionario Geschichtliche Grundbegriffe", en Santiago Castillo (coord.), La historia social en España. Actualidad y perspectivas, Siglo XXI, Madrid, 1991, pp. 47-63.

_., "En torno al objeto de la 'Historia de los conceptos' de Reinhart Koselleck", en Enrique Bocardo Crespo (comp.), El giro conceptual. Cinco ensayos de Quentin Skinner y seis comentarios, Tecnos, Madrid, 2007, pp. 215-248.

—, Democracia. Conceptos políticos fundamentales, Alianza, Madrid, 2011. 
Appleby, Joyce; Hunt, Lynn, y Jacob, Margaret, La verdad sobre la historia, Andrés Bello, Santiago de Chile, 1999.

Arendt, Hannah, La vida del espíritu, Paidós, Barcelona, 2002.

—, La condición humana, Paidós, Buenos Aires, 2005.

—, Sobre la revolución, Alianza, Madrid, 2013.

Austin, John, Cómo hacer cosas con palabras. Palabras y acciones, Paidós, Barcelona, 1990.

Barrionuevo, Sergio, "Khrónos y psykhé. Sobre una lectura heideggeriana de Aristóteles”, en Sebastián Torres y Julia Smolá (comps.), Lecturas contemporáneas de la filosofía política clásica y moderna, Universidad Nacional de General Sarmiento, Los Polvorines, 2012, pp. 131-146.

Barthes, Roland, "Le discours de l'histoire": Social Science Information, vol. VI, n. 4 (1967), pp. 63-75.

Blumenberg, Hans, La legitimidad de la Edad Moderna, Pre-Textos, Valencia, 2008.

Browning, Gary, "Quentin Skinner, the Cambridge School, and Contextualism”, en A History of Modern Political Thought. The Question of Interpretation, Oxford University Press, Oxford, 2016, pp. 67-88.

Brunner, Otto, Land und Herrschaft. Grundfragen der territorialen Verfassungsgeschichte Österreichs im Mittelalter [1939], Wissenschaftliche Buchgesellschaft, Darmstadt, 1984.

Boucher, David, Texts in Context. Revisionist Methods for Studying the History of Ideas, Dordrecht, Boston, Lancaster, 1985.

Carr, David, "Narrative and the Real World: An Argument for Continuity": History and Theory, vol. 25, n. ${ }^{\circ} 2$ (1986), pp. 117-131.

- Time, Narrative and History, Indiana University Press, Bloomington, 1991.

Certeau, Michel de, La escritura de la historia [1975], Universidad Iberoamericana, México, 2006.

Collingwood, Robin G., Una autobiografía, Fondo de Cultura Económica, México, 1953.

—, La idea de la historia, Fondo de Cultura Económica, México, 1965.

Derrida, Jacques, “La retirada de la metáfora": Cuaderno gris, n. 2 (1997), pp. 209-238.

—, De la gramatología, Siglo XXI, Buenos Aires, 2005.

Diès, Auguste, Autour de Platon, 2 vols., Gabriel Beauchesne, Paris, 1927.

Dunn, John, "The Identity of the History of Ideas": Philosophy, vol. 43, n. ${ }^{\circ}$ 164, (1968), pp. 85-104.

Duso, Giuseppe, La logica del potere: Storia concettuale come filosofia politica, Polimetrica, Monza, 2006.

Escohotado, Antonio, La conciencia infeliz. Ensayo sobre la filosofía de la religión en Hegel, Revista de Occidente, Madrid, 1972.

Esposito, Roberto, Diez pensamientos acerca de la política [1993], Fondo de Cultura Económica, México, 2012.

Fernández Sebastián, Javier, "Historia de los conceptos. Nuevas perspectivas para el estudio de los lenguajes políticos europeos": Ayer, n. ${ }^{\circ} 48$ (2002), pp. 331-372.

—, "Textos, conceptos y discursos políticos en perspectiva histórica": Ayer, n. 53 (2004), pp. 131-151.

—, “Qué es un diccionario histórico de conceptos políticos?”: Anales, n. ${ }^{7}$ 7-8 (2004-2005), pp. 223-240.

—, "Estado, nación y patria en el lenguaje político del siglo XIX": Revista de historia militar, número extraordionario (2005), pp. 159-220.

—, "Historia, historiografía, historicidad. Conciencia histórica y cambio conceptual", en Manuel Suárez Cortina (ed.), Europa del sur y América latina. Perspectivas historiográficas, Biblioteca Nueva, Madrid, 2014. 
Fernández Sebastián, Javier (coord.), Diccionario político y social del siglo XX español, Alianza, Madrid, 2008.

Fernández Sebastián, Javier, y Fuentes Aragonés, Juan Francisco (dirs.), Diccionario político y social del siglo XIX español, Alianza, Madrid, 2002.

Foucault, Michel, "El juego de Michel Foucault" [1977]: Diwan, n. 2 y 3 (1978), pp. 171202.

-, Las palabras y las cosas, Siglo XXI, Buenos Aires, 2002.

—, La arqueología del saber, Siglo XXI, Buenos Aires, 2004.

Halbwachs, Maurice, La memoria colectiva, Miño \& Dávila, Buenos Aires, 2011.

Heidegger, Martin, Hegel, en Gesamtausgabe, Bd. 68,Vittorio Klosterman, Frankfurt am Main, 1993.

— "Carta sobre el 'Humanismo"” [1946], en Hitos, Alianza, Madrid, 2001.

_, Aportes a la Filosofía: acerca del evento, Biblos, Buenos Aires, 2003.

-, Meditación, Biblos, Buenos Aires, 2005.

—, Sein und Zeit [1927], Max Niemeyer Verlag, Tübingen, 2006.

Hegel, G. W. F., La fenomenología del espíritu, Fondo de Cultura Económica, México, 2017.

Jablonka, Ivan, "Las operaciones de veridicción”, en La historia es una literatura contemporánea. Manifiesto por las ciencias sociales, Fondo de Cultura Económica, Buenos Aires, 2016, pp. 169-194.

Jay, Martin “La explicación histórica: reflexiones sobre los límites de la contextualización”: Prismas, n. ${ }^{\circ} 16$ (2012), pp. 145-157.

-, Exilios permanentes. Ensayos sobre la migración intelectual alemana en Estados Unidos, El cuenco de Plata, Buenos Aires, 2017.

Jordheim, Helge, “Against Periodization: Koselleck's Theory of Multiple Temporalities": History and Theory, vol. 51, $\mathrm{n}^{\circ} 2$ (2012), pp. 151-171.

Kant, Immanuel, Kritik der Urteilkraft [1793], en Immanuel Kants Werke, ed. de E. Cassirer et al., Verlegt bei Bruno Cassirer, Berlin, 1914.

King, Preston, "Historical Contextualism. The New Historicism?": History of European Ideas: vol. 21, n. 2 (1995), pp. 209-233.

Koselleck, Reinhart, "Geschichte, Historie”, en Geschichtliche Grundbegriffe. Historisches Lexikon zur politisch-sozialen Sprache in Deutschland, ed. de Otto Brunner, Werner Conze y Reinhart Koselleck, Klett-Cotta, Stuttgart, 1975.

—, Futuro pasado. Para una semántica de los tiempos históricos, Paidós, Barcelona, 1993.

_ , "The Temporalisation of Concepts": Finnish Yearbook of Political Thought, vol. 1 (1997), pp. 16-24.

—, Zeitschichten. Studien zur historik, Suhrkamp Taschenbuch Verlag, Frankfurt am Main, 2000.

—, "Introducción al Diccionario histórico de conceptos politico-sociales básicos en lengua alemana" [1972], trad. de Luis Fernández Torres: Anthropos, n. 233 (2009), pp. 92-105.

—, "Sobre la necesidad teórica de la ciencia histórica": Prismas, n. ${ }^{\circ} 14$ (2010), pp. 137-150.

_, "El siglo XVIII como comienzo de la Edad Moderna", en Modernidad, culto a la muerte y memoria nacional, Centro de Estudios Políticos, Madrid, 2011.

—, Historias de conceptos. Estudios sobre semántica y pragmática del lenguaje político y social, Trotta, Madrid, 2012.

Kuukkanen, Jouni-Matti, "Toward a Philosophy of the History of Thought": Journal of the Philosophy of History, vol. 3, n. ${ }^{\circ} 1$ (2009), pp. 25-54.

-, "Representationalism and Non-representationalism in Historiography": Journal of the Philosophy of History, vol. 7, n. 3 (2013), pp. 453-479. 
Lippard, Lucy R., Seis años: la desmaterialización del objeto artístico (de 1966 a 1972), Akal, Madrid, 2004.

Lorenz, Chris, "Historical Knowledge and Historical Reality: A Plea for 'Internal Realism"': History and Theory, vol. 33, n. ${ }^{\circ} 3$ (1994), pp. 297-327.

—, "Can Histories Be True?: Narrativism, Positivism and the 'Metaphorical Turn"”: History and Theory, vol. 37, n. ${ }^{\circ} 3$ (1998), pp. 309-329.

Löwith, Karl, Historia del mundo y salvación, Buenos Aires, Katz, 2007.

Lübbe, Hermann, Säkularisierung: Geschischte eines Ideenpolitischen Begriffs [1965], Verlag Karl Alber Freibutg, München, 2003.

Marchán Fiz, Simón, Del arte objetual al arte de concepto. Epílogo sobre la sensibilidad posmoderna, Akal, Madrid, 1990.

Marchant, Olvier, El pensamiento político posfundacional, Fondo de Cultura Económica, Buenos Aires, 2009.

Matravers, Darek y Pike, Jon (eds.), Debates in Contemporary Political Philosophy: An Anthology, Routledge, London, New York, 2003.

McCullagh, Christopher Behan, Justifying Historical Descriptions, Cambridge University Press, Cambridge, 1984.

- , The Truth of History, Routledge, New York, 1998.

Oncina, Faustino, "Historia conceptual, Histórica y la modernidad velociferina: diagnóstico y pronóstico de Reinhart Koselleck": Isegoría, n. ${ }^{\circ} 29$ (2003), pp. 211-237.

_ , "Necrológica del outsider Reinhart Koselleck: el historiador 'pensante' y las polémicas de los historiadores": Isegoría, n. ${ }^{\circ} 37$ (2007), pp. 35-61.

Palmer, Bryan D., Descent into Discourse, Temple University Press, Philadelphia, 1990.

Palti, Elías José, Aporías: Tiempo, Modernidad, Historia, Sujeto, Nación, Ley, Alianza, Buenos Aires, 2001.

—, "Reinhart Koselleck: His Concept of the Concept and Neo-Kantianism": Contributions to the History of Concepts, vol. 6, n. ${ }^{\circ} 2$ (2001), pp. 1-20.

- La nación como problema. Los historiadores y la "cuestión nacional”, Fondo de Cultura Económica, Buenos Aires, 2002.

—, "Koselleck y la idea de Sattelzeit: un debate sobre modernidad y temporalidad": Ayer, n. ${ }^{\circ}$ 53 (2004), pp. 63-74.

—, 'De la historia de 'ideas' a la historia de los 'lenguajes políticos'. Las escuelas recientes de análisis conceptual: el panorama latinoamericano": Anales, n. ${ }^{\circ}$ 7-8 (2004-2005), pp. 63-82.

—, "Temporalidad y refutabilidad de los conceptos políticos": Prismas, n. 9 (2005), pp. 19-34.

—, "El retorno del sujeto: subjetividad, historia y contingencia en el pensamiento moderno", en Manuel Cruz Rodríguez y Daniel Brauer, La comprensión del pasado: escritos sobre filosofía de la historia, Herder, Barcelona, 2005, pp. 265-304.

—, El tiempo de la politica: el siglo XIX reconsiderado, Siglo XXI, Buenos Aires, 2007.

—, "The 'Theoretical Revolution' in Intellectual History: From the History of Political Ideas to the History of Political Languages": History \& Theory, vol. 53, n. ${ }^{\circ} 3$ (2014).

Peterson, Erick, El monoteismo como problema político, Trotta, Madrid, 1999.

Pocock, John Greville Agard, "The History of Political Thought: A Metodological Inquiry", en Peter Laslett y W. G. Runciman, Philosophy, Politics and Society, Blackwell, Oxford, 1962, pp. 183-202.

Quine, Willard, “On What There Is”, en From a Logical Point of View, Harper \& Row, New York, 1953. 
Ranke, Leopold von, Pueblos y Estados en la historia moderna, Fondo de Cultura Económica, México, 1948.

Rawls, John, Teoría de la justicia, Fondo de Cultura Económica, México, 1995.

—, Liberalismo político, Crítica, Barcelona, 1996.

Romano, Claude, L'Événement et le temps, Presses Universitaires de France, Paris, 1999.

—, El acontecimiento y el mundo, Biblos, Buenos Aires, 2017.

Runia, Eelco, "Presence": History and Theory, vol. 45, n. ${ }^{\circ} 1$ (2006), pp. 1-29.

—, "Spots of Time": History and Theory, vol. 45, n. 3 (2006), pp. 305-316.

Rosanvallon, Pierre, Para una historia conceptual de lo político, Fondo de Cultura Económica, México, 2003.

Skinner, Quentin, "Meaning and Understanding in the History of Ideas": History and Theory vol. 8, n. ${ }^{\circ} 1$ (1969), pp. 3-53.

- "Conventions and the Understanding of Speech Acts": The Philosophical Quarterly, vol. 20, n. ${ }^{\circ} 79$ (1970), pp. 118-138.

Strauss, Leo, The Argument and Action of Plato's Laws, University of Chicago Press, Chicago, 1975.

_-, La persecución y el arte de escribir, Amorrortu, Buenos Aires, 2009.

-, Derecho natural e historia, Prometeo, Buenos Aires, 2013.

Sazbón, José, "La devaluación formalista de la historia", en Ezequiel Adamovsky (comp.), Historia y sentido, El Cielo por Asalto, Buenos Aires, 2001.

Scheperd, Michael, “Tiempo de lo real y tiempo del lógos": Diógenes, n. 74 (1971), pp. 31-44.

Schmitt, Carl, Teología política, Trotta, Madrid 2009.

—, El concepto de lo político, Alianza, Madrid, 2014.

Tozzi, Verónica, "La 'reconstrucción histórica'. Acerca de los supuestos epistemológicos de la explicación y narración historiográfica": Revista de filosofia, vol. 22, n. ${ }^{\circ} 1$ (1996), pp. 55-68.

—, "El relato histórico: ¿hipótesis o ficción? Críticas al 'narrativismo imposicionalista' de Hayden White”: Análisis Filosófico,vol. 17, n. ${ }^{\circ} 1$ (1997), pp. 75-93.

—, "Historización, contextualización y perspectiva", en Eduardo Sota y Luis Urtubey, Epistemología e Historia de la Ciencia (Selección de trabajos de las IX Jornadas), vol. 5, n. ${ }^{\circ}$ 5 (1998), pp. 494-501.

Vásquez Rocca, Adolfo, “Arte conceptual y postconceptual. La idea como arte: Duchamp, Beuys, Cage y Fluxus": Nómadas. Revista Crítica de Ciencias Sociales y Jurídicas, vol. 37, n. ${ }^{\circ} 1$ (2013), pp. 1-29.

Villacañas, José Luis, "Histórica, historia social e historia de los conceptos políticos": Res publica, n. ${ }^{\circ}$ 11-12 (2003), pp. 69-94.

Villacañas, José Luis, y Oncina, Faustino, “Introducción”, en Reinhart Koselleck y HansGeorg Gadamer, Histórica y Hermenéutica, Paidós, Barcelona, 1997, pp. 9-54.

White, Hayden, "El valor de la narrativa en la representación de la realidad" [1980], en El contenido de la forma. Narrativa, discurso y representación histórica, Paidós, Buenos Aires, 1992, pp. 17-39.

—, "Against Historical Realism. A Reading of War and Peace": New Left Review, n. 46 (2007), pp. 89-110.

—, Metahistoria, Fondo de Cultura Económica, Buenos Aires, 2010, pp. 86-132.

_ , "Romanticism, Historicism, and Realism: Toward a Period Concept for Early Nineteenth-Century Intellectual History" [1968], en The Fiction of Narrative: Essays on History, Literature, and Theory (1957-2007), The Johns Hopkins University Press, Baltimore, 2010. 
—, "The Discourse of History" [1979], en The Fiction of Narrative: Essays on History, Literature, and Theory (1957-2007), The Johns Hopkins University Press, Baltimore, 2010.

Wittgenstein, Ludwing, Investigaciones filosóficas, Crítica, Barcelona, 2004.

Zagorin, Perez, "Historiography and Postmodernism: Reconsiderations": History and Theory, vol. 29, n. ${ }^{\text {o }} 3$ (1990), pp. 275-296.

—, "History, the Referent and Narrative: Reflections on Postmodernism Now": History and Theory, vol. 38, n. ${ }^{\circ} 1$ (1999), pp. 1-24.

Yerushalmi, Yosef Hayim, "Reflexiones sobre el olvido", en Usos del olvido. Comunicaciones al coloquio de Royaumont, Nueva Visión, Buenos Aires, 1989.

Zammito, John, "Ankersmit and Historical Representation": History and Theory, vol. 44, n. ${ }^{\text {o }}$ 2 (2005), pp. 155-181.

Zeleňák, Eugen, "Two Versions of a Constructivist View of Historical Work": History and Theory, vol. 54, n. ${ }^{\circ} 2$ (2015), pp. 209-225. 